Editorial

\title{
The challenge of an adequate outcome in trials for genetic eye disease such as Leber Hereditary Optic Neuropathy (LHON)
}

\author{
David A Mackey MD FRANZCO ${ }^{1,2,3}$ and Lisa S Kearns BOrth\&OphthSci(Hons) \\ GradDipGenCounsel $^{2}$
}

1. Centre for Ophthalmology and Visual Science, Lions Eye Institute, University of Western Australia, Perth, Australia

2. Centre for Eye Research Australia, University of Melbourne, Royal Victorian Eye and Ear Hospital, Melbourne, Australia

3. Menzies Research Institute, University of Tasmania, Hobart, Australia

Correspondence: David A Mackey, Lions Eye Institute, 2 Verdun St, Nedlands, WA 6008, Australia

D.Mackey@utas.edu.au

Funding sources / Financial disclosure: Supported by a grant from the Ophthalmic Research Institute of Australia

Conflict of interest: None

This is the author manuscript accepted for publication and has undergone full peer review but has not been through the copyediting, typesetting, pagination and proofreading process, which may lead to differences between this version and the Version of Record. Please cite this article as doi: 10.1111/ceo.13586

This article is protected by copyright. All rights reserved. 
With improvements in screening and management for eye diseases such as diabetic retinopathy, Inherited Eye Diseases (IEDs), in particular Inherited Retinal Diseases (IRDs), are becoming the leading cause of blindness for working age adults in developed countries. Hundreds of genes causing IEDs have been discovered. Once confirmed, a genetic diagnosis can lead to a better understanding of the likely natural history, phenotype-genotype correlations and possible eligibility for enrolment in research and clinical trials.

Gene-based therapies, notably Adeno-Associated Virus (AAV) gene therapy trials, are underway for many genetic subtypes of IRD. ${ }^{(1)}$ To date, one gene therapy Voretigene neparvovec $\square$ rzyl (Luxturna ${ }^{\circledR}$ ) - has been licenced in the US, but not yet in Australia. A major challenge for all the trials is the slow (but relentless) progression of most IRDs. In many cases, the test-retest variability of most measures of vision loss is greater than the annual progression of disease. New tests, such as microperimetry, retinal imaging and electrophysiology, have been developed. Even with these new technologies it will still take years to show any meaningful reduction in progression of disease and natural history trials with these technologies are pending. In some cases, restoration of function, such as improved night vision (and navigation in a dim lit environment) in RPE65 patients treated with Luxturna ${ }^{\circledR}$, are useful indicators of efficacy. But how well Luxturna ${ }^{\circledR}$ prevents vision loss over decades remains to be determined.

Leber Hereditary Optic Neuropath (LHON) is an exception to most IEDs, with an acute, dramatic loss of vision in both eyes (from 6/4.8 to 6/120 or loss of 14 lines) in a matter of days or weeks. Despite visual acuity being the most measured parameter in ophthalmic practice, it is analysed infrequently in epidemiology studies. We have minimal data on the population distribution of visual acuity over different ages and very little on the usual changes with aging from childhood to old age. Moreover, the 
test-retest changes of visual acuity are not well established. The Early Treatment of Diabetic Retinopathy Study helped institute a more standard testing protocol and the "cutoff" for improvement was given as 3 lines of vision on the ETDRS chart for diabetic maculopathy. This was later used in age-related macular degeneration studies. ${ }^{(2)}$ Visual acuity is not an objective test. The education and experience of the patient and the level of encouragement from the person testing, as well as other subtle changes in factors such as illumination and general wellbeing of the patient, can influence a result. In addition, patients with central vison loss learn to use their remaining field, identifying eccentric fixation to allow them to see better.

Such a dramatic loss of vision and the very high likelihood of vision loss in the second eye meant that early trials of LHON treatment were optimistic in showing a successful result with small numbers of patients. ${ }^{(3)}$ Idebenone showed initial promise with a single case of the 11778 LHON mutation, ${ }^{(4)}$ but later reports were mixed, leading to a randomised clinical trial that was not really conclusive as to the efficacy of idebenone. ${ }^{(5)}$ A major problem with LHON is the well documented natural history of partial visual recovery without any treatment (particularly with some genetic subtypes [14484mtDNA and 3460mtDNA] and in younger individuals). Even with the poorer prognosis and the more common 11778 mutation, spontaneous recovery is seen. ${ }^{(6)}$ Visual prognosis is better in eyes with less severe reduction of visual acuity one year after onset. Visual acuity corresponds with visual field indices in the decline of vision in LHON. ${ }^{(7)}$ Thus an ideal study needs to be a masked clinical trial with treated and untreated patients. The unmasked LHON AAV gene therapy trials have been run in China, Europe and the US, and unfortunately only mild evidence of slight improvement was found. ${ }^{(8-10)}$ The studies have compared the treated and untreated eye, presuming the untreated eye would be an adequate control. However, the untreated eyes have also shown improvement. This leaves us wondering if the improvement is just a placebo effect or bilateral natural history of improvement or 
alternatively is there a retrochiasmal cross-over of the treatment effect? Does treating an adjacent axon from the contralateral eye benefit axons in the untreated eye?

The study of Zhang and colleagues in this journal ${ }^{(11)}$ is a continuation of their earlier trial; ${ }^{(10)}$ they have now treated 53 patients with the 11778 mutation. The major findings of this study, in which half the patients had lost vision more than 2 years earlier, was that more than half the participants had vision improve more or equal to three lines at 3 months after treatment. However, those who recovered were more likely to have had better vision and visual field parameters (VFI and MD) at the time of treatment - the same indicators for increased likelihood of spontaneous improvement.

While three lines of improvement would benefit many patients, it is a long way from recovery in LHON where often 14 lines have been lost. With uncertainty as to whether gene therapies or idebenone really do give three lines of recovery, is this cost of $\$ 100,000$ or $\$ 1,000,000$ worthwhile when this money could be spent on adaptive technology and other forms of low-vision assistance for these patients?

The current trials show excellent safety profiles. However, we may need to treat people in the unaffected eye prior to vision loss of the second eye, i.e. the same enrolment as the earlier brimonidine trial. ${ }^{(3)}$ These trials will take longer to conduct and will have a major challenge to recruit and treat patients in this narrow window period. While patients, clinicians, safety committees, institutional review boards and ethics committees would want this research, we hope that funders and shareholders will continue to support such challenging trials. 
The incorporation of genomics information into healthcare is steadily increasing. In Australia a major study called "Mackenzie's Mission" will offer genetic carrier screening to 10,000 couples for 500 autosomal recessive and X-linked conditions to identify those who are at increased risk of having a child with a rare genetic disease. ${ }^{(12)}$ This aims to help facilitate informed reproductive decision-making and couples have the option to take steps to avoid having an affected child.

What options are available for LHONmtdNA female carriers? Some may choose to fall pregnant naturally. Others may consider having a non-biologically related child through adoption or egg or embryo donation to avoid passing on the LHON mtDNA mutation to the next generation. Mitochondrial donation may be another option and is now approved for use in the United Kingdom. In this scenario, the mitochondria of the mother is "replaced" with healthy mitochondria from a donor egg. A baby is created via an IVF (in vitro fertilization) procedure that involves three people: the mother, the father and a woman who donated eggs to prevent LHON vision loss in future children. However, further research will be necessary to fully understand the long-term effects of this therapy.

But in our enthusiasm to capitalise on the genomics revolution to treat and prevent IEDs, most of which is years away, are we missing the great revolution in rehabilitation that is underway with Artificial Intelligence and smart device technology that is available now in Apps such as Seeing Al (developed by Microsoft and available free to download). ${ }^{(13)}$

\section{REFERENCES}

1. Ramlogan-Steel CA, Murali A, Andrzejewski S, Dhungel B, Steel JC, Layton C). Gene therapy and the adeno-associated virus in the treatment of genetic and 
acquired ophthalmic diseases in humans: Trials, future directions and safety considerations. Clin Exp Ophthalmol. 2019;47(4):521-36.

2. Rosenfeld PJ, Brown DM, Heier JS, Boyer DS, Kaiser PK, Chung CY, et al. Ranibizumab for neovascular age-related macular degeneration. N Engl J Med. 2006; 355(14): 1419-31.

3. Newman NJ, Biousse V, David R, Bhatti MT, Hamilton SR, Farris BK, et al. Prophylaxis for second eye involvement in leber hereditary optic neuropathy: an open-labeled, nonrandomized multicenter trial of topical brimonidine purite. Am J Ophthalmol. 2005;140(3):407-15.

4. Mashima Y, Hiida Y, Oguchi Y. Remission of Leber's hereditary optic neuropathy with idebenone. Lancet. 1992;340(8815):368-9.

5. Klopstock T, Yu-Wai-Man P, Dimitriadis K, Rouleau J, Heck S, Bailie M, et al. A randomized placebo-controlled trial of idebenone in Leber's hereditary optic neuropathy. Brain. 2011;134(Pt 9):2677-86.

6. Lam BL, Feuer WJ, Schiffman JC, Porciatti V, Vandenbroucke R, Rosa PR, et al. Trial end points and natural history in patients with G11778A Leber hereditary optic neuropathy : preparation for gene therapy clinical trial. J AMA Ophthalmol. 2014; 132(4):428-36.

7. Mashima Y, Kigasawa K, Shinoda K, Wakakura M, Oguchi Y. Visual prognosis better in eyes with less severe reduction of visual acuity one year after onset of Leber hereditary optic neuropathy caused by the 11,778 mutation. BMC Ophthalmol. 2017;17(1): 192.

8. Guy J, Feuer WJ, Davis J L, Porciatti V, Gonzalez PJ, Koilkonda RD, et al. Gene Therapy for Leber Hereditary Optic Neuropathy: Low- and Medium-Dose Visual Results. Ophthalmology. 2017;124(11):1621-34.

9. Vignal C, Uretsky S, Fitoussi S, Galy A, Blouin L, Girmens JF, et al. Safety of rAAV2/2-ND4 Gene Therapy for Leber Hereditary Optic Neuropathy. Ophthalmology. 2018; 125(6):945-7. 
10. Yang S, Ma SQ, Wan X, He H, Pei H, Zhao MJ, et al. Long-term outcomes of gene therapy for the treatment of Leber's hereditary optic neuropathy. EBioMedicine. 2016; 10:258-68.

11. Zhang Y, Li X, Yuan J, Tian Z, Liu H, Wang D, et al. Prognostic factors for visual acuity in patients with Leber's hereditary optic neuropathy after rAAV2-ND4 gene therapy. Clin Exp Ophthalmol. 2019.

12. Emery J, Delatycki MB, Laing NG, Moore SJ , Archibald AD, Massie J, et al. Preconception and antenatal carrier screening for genetic conditions: The critical role of general practitioners. Aust J Gen Pract. 2019;48(3):106-10.

13. https://www.microsoft.com/en-us/ai/seeing-ai. 


\section{University Library}

\section{- M M I N E R VA A gateway to Melbourne's research publications}

Minerva Access is the Institutional Repository of The University of Melbourne

Author/s:

Mackey, DA;Kearns, LS

Title:

The challenge of an adequate outcome in trials for genetic eye disease such as Leber hereditary optic neuropathy

Date:

2019-08-01

Citation:

Mackey, D. A. \& Kearns, L. S. (2019). The challenge of an adequate outcome in trials for genetic eye disease such as Leber hereditary optic neuropathy. CLINICAL AND EXPERIMENTAL OPHTHALMOLOGY, 47 (6), pp.704-705. https://doi.org/10.1111/ceo.13586.

Persistent Link:

http://hdl.handle.net/11343/286236 